\title{
Effects of waste ground glass and lime on the crystallinity and strength of geopolymers
}

\author{
Abdollahnejad Z. ${ }^{1 *}$, Dalvand A. ${ }^{2}$, Mastali M. ${ }^{3}$, Luukkonen T. ${ }^{4}$, Illikainen M. ${ }^{5}$ \\ 1. Fibre and Particle Engineering, Faculty of Technology, Univ. of Oulu, P.O. Box 4300, 90014 Oulu, \\ Finland *Corresponding author Email: Zahra.abdollahnejad@oulu.fi \\ 2. Department of Engineering, Lorestan University, Khorramabad, Iran. Email: Dalvand.a@lu.ac.ir \\ 3. Fibre and Particle Engineering, Faculty of Technology, Univ. of Oulu, P.O. Box 4300, 90014 Oulu, \\ Finland. Email: Mohammad.mastali@oulu.fi \\ 4. Fibre and Particle Engineering, Faculty of Technology, Univ. of Oulu, P.O. Box 4300, 90014 Oulu, \\ Finland. Email: Tero. Luukkonen@oulu.fi \\ 5. Fibre and Particle Engineering, Faculty of Technology, Univ. of Oulu, P.O. Box 4300, 90014 Oulu, \\ Finland. Email: Mirja.Illkanien@oulu.fi
}

\begin{abstract}
This study investigates the effects of adding waste ground glass and lime (calcium hydroxide) on the microstructural properties of amorphous gels transitioning into crystallized zeolites in fly ashbased geopolymers. Three different mix compositions were synthesized using fly ash, waste ground glass powder, and calcium hydroxide. These mixtures were subjected to accelerated aging by thermal curing (at a temperature of $80^{\circ} \mathrm{C}$ ), the treatment lasting for 56 days. Crystalline zeolitic phases were detected by Fourier transform infrared spectroscopy and X-ray diffraction. The results show that the transition from amorphous gels into more ordered structures readily occurred in the compositions employing only waste ground glass or calcium hydroxide, while a combination of waste ground glass and calcium hydroxide hindered the transition. Moreover, the topographical images of the compositions indicate a greater degree of roughness in the mixture with a lower degree of transition from the amorphous gels into more ordered structures.

It was revealed that crystallization had no harmful effect on the strength stability of the compositions cured for 28 days at a temperature of $80^{\circ} \mathrm{C}$. In fact, the maximum increase in the compressive strength occurred due to the formation of crystalline zeolites in fly ash based geopolymers.
\end{abstract}

Keywords: Crystallization, waste ground glass, fly ash-based geopolymers, calcium hydroxide, accelerated aging 


\section{Introduction}

Geopolymers are considered X-ray amorphous analogues of zeolites and, in fact, they contain nanometer-scale zeolite phases (Provis et al., 2005a). However, zeolite synthesis is typically different compared to geopolymer formation in terms of the higher water amount (i.e., more dilute reaction conditions), higher temperature (typically $80-200^{\circ} \mathrm{C}$ ), longer reaction times, and a closed system (i.e., elevated pressure) (Van Jaarsveld et al., 2002; Cundy et al., 2003; Van Jaarsveld et al., 1998; Querol et al., 2002). The reaction sequence and related kinetics leading to the formation of either amorphous aluminosilicate gels or crystalline zeolitic phases from an aluminosilicate precursor were described by Provis and van Deventer (Provis and Van Deventer, 2007). The formation of crystalline zeolites during geopolymer synthesis is unfavorable (for example, due to reaction kinetics) and therefore, their amount should be typically low or non-existent (FernándezJiménez et al., 2006). However, several factors increase the tendency of zeolite crystal growth during geopolymerization, including a low $\mathrm{SiO}_{2} / \mathrm{Al}_{2} \mathrm{O}_{3}$ ratio in the reaction mixture, presence of a sufficiently low amount of nucleation sites, increase in the temperature, and increase in the alkalinity (Provis et al., 2005a; Ruiz-Santaquiteria et al., 2012). All of the aforementioned aspects affect the rate of nucleation and degree of supersaturation of the solution to favor zeolite formation (Provis et al., 2005a).

Zeolites can be categorized as a mineral class called tectosilicates, in which quartz $\left(\mathrm{SiO}_{2}\right)$ defines the structure of the zeolite; however, it is to be kept in mind that zeolites and quartz are different (Grutzeck et al., 2004). Zeolites with open structures are formed around large solvated cations, such as sodium $(\mathrm{Na})$ or potassium $(\mathrm{K})$. It has been proposed that the formation of zeolite from geopolymers (which is a metastable phase) occurs through a solid-phase transformation mechanism (Yan et al., 2012). In short, depolymerization and structural rearrangement of geopolymers occur though the catalytic activity of hydroxyl ions, which results in the formation of primary structural units necessary for zeolite crystallization (Xu et al., 2007). Consequently, the rearrangement of these primary structural units leads to the formation of polyhedra around hydrated cations, which can further polymerize and form zeolite crystals (Xu et al., 2007). Geopolymers can also be transformed into zeolites by hydrothermal aging, i.e., submersing geopolymers in water or dilute $\mathrm{NaOH}$ solution at approximately $90{ }^{\circ} \mathrm{C}$ for several hours (Xuemin et al., 2011; He et al., 2013; Zhang et al., 2014; Zhang et al., 2016). The presence of small amounts of zeolites can be beneficial for strength development owing to the crystallization contact between the zeolite and amorphous phases (Van Jaarsveld et al., 1998); further, zeolites can fill the porous spaces in the matrix (Palomo et al., 1999). 
Lloyd investigated the effects of zeolite formation on the strength development in metakaolinbased geopolymer concrete under thermal aging conditions of $95{ }^{\circ} \mathrm{C}$ for 28 days (Lloyd et al., 2009). A zeolitic Na-P1 phase was formed and its amount greatly increased during the 28 days of aging, whereas its compressive strength reduced. The formation of zeolite (type Na-P1) in fly ash-based geopolymers under thermal aging conditions of $95{ }^{\circ} \mathrm{C}$ for 28 days (Lloyd et al., 2009) did not lead to any loss in strength. Moreover, it was observed that the amount of formed crystallites strongly depended on the alkali concentration.

Criado et al. (Criado et al., 2005) showed that by thermal curing at temperatures of $85^{\circ} \mathrm{C}$ from 5 hours to 7 days in alkali-activated fly ash binders enhanced the compressive strength and increased the degree of crystallinity (Criado et al., 2005). Criado et al. also investigated the effects of thermal curing (temperature of $85{ }^{\circ} \mathrm{C}$ ) on the silica content in alkali-activated fly ash-based binders (Criado et al., 2007). They found that the primary reaction product was a sodium aluminosilicate gel, while different types of zeolites appeared as secondary reaction products, and these reaction products were dependent on the silica content and thermal curing conditions (Criado et al., 2007). Increasing the time of thermal curing increased the zeolite formation but also increased the compressive strength; this strength increase was caused by the gel transitions in fly ash-based binders. A high content of crystalline zeolites prevented high mechanical strength development due to induced inner stresses or even local destruction. Additionally, the results provided some evidence that using a greater amount ofsilica in the activating solution postponed the degree of ash reaction and zeolite formation due to the higher degree of polymerization of silica (Criado et al., 2007). Nonetheless, more thermodynamically stable products are formed at longer thermal curing times. The mechanical strength development of these binders is affected by both the reaction degree and nature of the reaction products (Criado et al., 2007).

One of the most important factors in geopolymer gel formation is the content of reactive (i.e., amorphous) silica and alumina (Torres-Carrasco and Puertas, 2015). High content of silica species of the waste ground glass provides this opportunity to use this material as the silica source in preparation of alkali-activated mortars, which the usage of waste components would help in conserving the earth's natural resources, saves energy, money, and reduces $\mathrm{CO}_{2}$ emissions and other greenhouse gases. Apart from the content of reactive silica and alumina, the calcium content also plays an important role in gel formation and strength development.

To the best of the authors' knowledge, an extensive experimental/analytical study on the impact of using waste ground glass and calcium hydroxide on the crystallinity and strength of alkaliactivated fly ash mortars has not been conducted thus far although some studies have been conducted on the effects of alkali solutions on the crystallinity and strength of fly ash-based 
geopolymer mortars (Ma et al., 2016). Therefore, this study aims to investigate the microstructural effects of using waste ground glass as the source of silica and calcium hydroxide as the source of calcium on the phase transition of fly ash-based geopolymers cured at different aging conditions. This investigation analyzes the formation of the primary and secondary reaction products on the strength loss or gain due to postponed phase transition in the compositions containing waste ground glass and calcium hydroxide.

\section{Experimental program}

\section{Materials and mix designs}

The designed geopolymers were composed of fly ash (FA), calcium hydroxide $(\mathrm{CH})$, milled glass (MG), fine aggregate, sodium silicate solution (molar ratio of $\mathrm{SiO}_{2} / \mathrm{Na}_{2} \mathrm{O}: 2.5$ ), and sodium hydroxide solution (10 mol/L, prepared with $99 \%$ pure pellets). The alkali solution was prepared by mixing sodium silicate and sodium hydroxide with ratio of 2.5 .

The chemical composition of fly ash and waste ground glass were determined by X-ray fluorescence (XRF) and the results are shown in Table 1. Regarding the chemical composition, the used fly ash was a low-calcium fly ash $(\mathrm{CaO} \leq 10 \%)$. Waste ground glass, which was used as a source of amorphous silica, was produced using glass juice bottles, ground for five hours on a laboratory-scale ball mill. Waste ground glass was also prepared by mixing waste glasses (transparent and colorful)After milling, the dimension of the waste glass particles measured by laser diffraction particle sizing technique and the dimension of particles were lower than $50 \mu \mathrm{m}$. Calcium hydroxide (or lime) was comprised of $\mathrm{Ca}(\mathrm{OH})_{2} \geq 99 \%$ and $\mathrm{MgO} \leq 0.35 \%$. Using sieves, sand particles (aggregates) distributed between a minimum diameter of $0.2 \mathrm{~mm}$ (No. 10) and a maximum diameter of $4.0 \mathrm{~mm}$ (No. 5) were used in this study (ASTM C136 / C136M-14, 2014). 
Table 1. Chemical composition, density, and loss on ignition (LOI) of fly ash and waste ground glass (in wt.\%)

\begin{tabular}{|c|c|c|}
\hline Composition & Fly ash & Waste milled glass \\
\hline $\mathrm{SiO}_{2}$ & 72.10 & 66.37 \\
\hline $\mathrm{Al}_{2} \mathrm{O}_{3}$ & 24.70 & 1.71 \\
\hline $\mathrm{Fe}_{2} \mathrm{O}_{3}$ & 1.05 & 2.13 \\
\hline $\mathrm{MgO}$ & 0.18 & 0.29 \\
\hline $\mathrm{K}_{2} \mathrm{O}$ & 0.50 & 0.68 \\
\hline $\mathrm{Na}_{2} \mathrm{O}$ & 0.10 & 11.93 \\
\hline $\mathrm{CaO}$ & 0.10 & 10.76 \\
\hline $\mathrm{TiO}_{2}$ & 1.20 & 0.04 \\
\hline $\mathrm{SO}_{3}$ & $\leq 0.10$ & 0.14 \\
\hline Density $\left(\mathrm{g} / \mathrm{cm}^{3}\right)$ & 0.80 & 1.27 \\
\hline $\mathrm{LOI}(\%)$ & 0.90 & 0.85 \\
\hline
\end{tabular}

Fig. 1 shows the mineral composition of the samples analyzed by X-ray diffraction (XRD) at a scan rate of $0.5 \mathrm{~s}$ per step with the board peak $(2 \theta)$ between $5^{\circ}$ to $80^{\circ}$. Fly ash contains several crystalline phases, including mullite $\left(\mathrm{Al}_{2.35} \mathrm{Si} .64 \mathrm{O}_{4.82}\right)$, quartz $\left(\mathrm{SiO}_{2}\right)$, and magnetite $\left(\mathrm{Fe}_{3} \mathrm{O}_{4}\right)$. The highly amorphous nature of waste ground glass can be deduced from its XRD pattern, in which only a broad amorphous halo can be observed. Because reactive silica and alumina play a critical role in gel formation, the expected high content of silica in the waste ground glass shows that it could be used as a source of silica in the preparation of geopolymers, but the low aluminum content $(\sim 1.5 \mathrm{wt} . \%)$ requires the incorporation of fly ash in the mixtures as a source of aluminum.

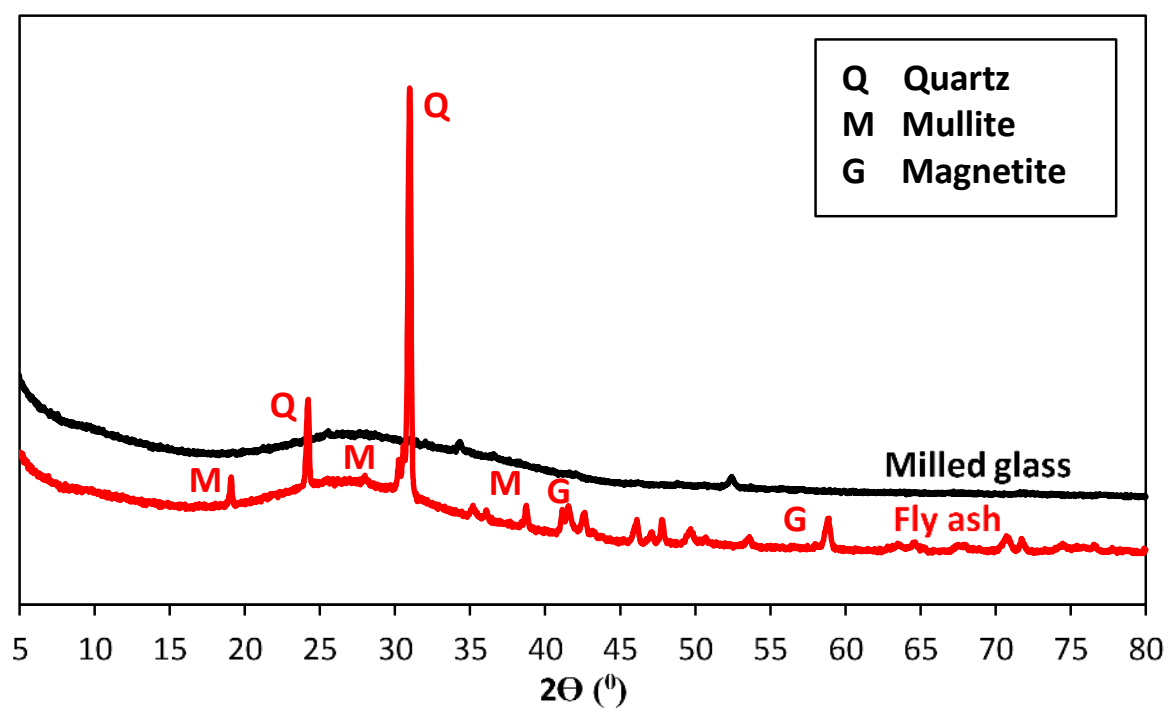

Fig 1. XRD patterns of fly ash and waste ground glass 


\section{Specimen synthesis and aging}

In the present study, four different compositions were investigated using different combinations of binder components. The content of fly ash in all the mixtures (except the reference mixture) was constant and equal to 0.8 times the total binder weight, while the rest $20 \%$ of the binder weight was assigned to calcium hydroxide or/and waste ground glass. The content of binder was selected based on the investigation in (Mastali et al., 2018). The mix proportions are listed in Table 2.

Table 2. Mixture proportions and designations

\begin{tabular}{|c|c|c|c|c|c|c|}
\hline $\begin{array}{c}\text { Mixture } \\
\text { notation }\end{array}$ & $\begin{array}{c}\text { Fly } \\
\text { ash }\end{array}$ & $\begin{array}{c}\text { Calcium } \\
\text { hydroxide }\end{array}$ & $\begin{array}{c}\text { waste } \\
\text { ground } \\
\text { glass }\end{array}$ & Alkali/binder* & $\begin{array}{c}\text { Sodium } \\
\text { silicate/sodium } \\
\text { hydroxide }\end{array}$ & Sand/binder \\
\cline { 1 - 3 } M1 & 80 & 20 & 0 & & & \\
\cline { 1 - 3 } M2 & 80 & 10 & 10 & \multirow{2}{*}{0.8} & & 0.85 \\
\cline { 1 - 3 } M3 & 80 & 0 & 20 & & & \\
\hline M4 & 100 & 0 & 0 & & & \\
\hline
\end{tabular}

Binder*: fly ash + calcium hydroxide + waste ground glass

In the first mixture (M1), the content of calcium hydroxide was $20 \%$ of the total binder weight, while in the second mixture (M2), the content of both calcium hydroxide and waste glass were changed to $10 \%$. In the mix composition (M3), the content of waste glass was $20 \%$ of the total binder weight. The last mixture (M4) was assigned to the reference mixture with $100 \%$ fly ash and waste ground glass and lime did not use. When the composition changes from M1 to M3, it increases the reactive silica amount and reduces the calcium content in the mix compositions. The main aim of these compositions was to study the effects of using waste ground glass as the source of reactive silica and calcium hydroxide as the source of calcium on the transition of alkaliactivated fly ash-based mortar gels into ordered structures and their compressive strength. The calculated chemical compositions of the mixtures are listed in Table 3. Based on the different percentages of silica and calcium contents, eighteen cubic specimens were cast and tested to assess the compressive strength of each composition. The specimen designation used is explained in Fig. 2. 


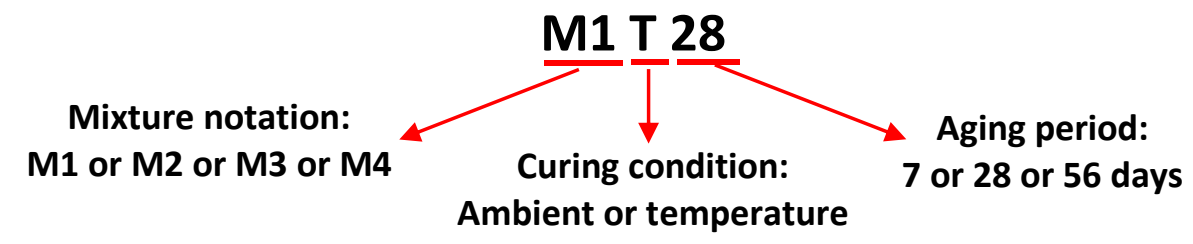

Fig 2. Specimen notation for binders

Table 3. Chemical compositions of the mixtures

\begin{tabular}{|c|c|c|c|c|}
\hline Mixture notation & $\mathbf{S i O}_{2} / \mathbf{A l}_{2} \mathbf{O}_{3}$ & $\mathbf{A l}_{2} \mathbf{O}_{3} / \mathbf{N a}_{2} \mathbf{O}$ & $\mathbf{C a O} / \mathbf{S i O}_{2}$ & $\mathbf{N a}_{2} \mathbf{O} / \mathbf{C a O}$ \\
\hline $\mathbf{M 1}$ & 8.46 & 0.54 & 0.21 & 0.99 \\
\hline $\mathbf{M} 2$ & 9.32 & 0.54 & 0.09 & 1.98 \\
\hline M3 & 10.18 & 0.54 & 0.001 & 247.79 \\
\hline M4 & 4.95 & 0.84 & 0.001 & 160.68 \\
\hline
\end{tabular}

The dry ingredients (fly ash, sand, calcium hydroxide, (and/or) milled waste ground glass) were initially stirred for 2 min after which the reaction was initiated by the addition of the activator solutions to the solid materials. Mixing was continued for another $3 \mathrm{~min}$. Later, the fresh mortars were cast into cubic molds of $50 \times 50 \times 50 \mathrm{~mm}^{3}$ dimensions to assess the compressive strength after hardening (ASTM C109 / C109M-16a, 2016). The specimens were cured at the ambient conditions (unsealed and exposed to the air) with an average temperature of $25{ }^{\circ} \mathrm{C}$ and $30 \%$ relative humidity $(\mathrm{RH})$ for $24 \mathrm{~h}$ after which they were demolded.

Such an initial low-temperature curing condition $\left(60-80^{\circ} \mathrm{C}\right)$ aids strength development in fly ash geopolymers (Hardjito, 2005; Winnefeld et al., 2010). Subsequently, some unsealed specimens were moved to a lab oven and subjected to thermal curing at $(80 \pm 1){ }^{\circ} \mathrm{C}$. At 7,28 , and 56 days, the specimens were taken out from their containers, equilibrated to room temperature, and tested under compressive loading conditions. In addition, some specimens were also cured the room temperature $\left(25^{\circ} \mathrm{C}\right)$ and $30 \% \mathrm{RH}$ for 7,28 , and 56 days.

\section{Test procedures and setups}

\section{Compressive test}

As mentioned previously, two different regimes were used to cure the cubic specimens. Some specimens were cured in the oven (thermal curing at $(80 \pm 1){ }^{\circ} \mathrm{C}$ ) and the rest cured at lab conditions $\left(25{ }^{\circ} \mathrm{C}\right.$ and $\left.30 \% \mathrm{RH}\right)$. All the specimens were assessed under compressive loading conditions with a constant displacement rate of $1.8 \mathrm{~mm} / \mathrm{min}$, based on the ASTM C109 recommendations (ASTM C109 / C109M-16a, 2016). The compressive load was measured with 
a load cell of $200 \mathrm{kN}$ capacity. Three specimens were tested for each mix composition at different ages to obtain mean values.

\section{Microstructural analysis}

The chemical bonds and morphologies of the cubic specimens were identified using Fourier transform infrared spectroscopy (FTIR) and scanning electron microscopy (SEM), respectively. FTIR spectra were acquired in the attenuated total reflectance (ATR) mode using a Perkin Elmer FTIR Spectrum BX instrument with an ATR PIKE MIRacle unit. Spectral analysis was executed over the range of $4000-550 \mathrm{~cm}^{-1}$ at a spectral resolution of $4 \mathrm{~cm}^{-1}$.

$X-R a y$ Diffraction (XRD) was performed to investigate the crystalline phases in the specimens and the effects of thermal curing on the phase identification of crystalline materials. The XRD data was collected using a Bruker D8 Advance X-ray diffractometer with Ni-filtered Cu radiation (1.54 $\AA$ ) at $40 \mathrm{~mA}$ and $40 \mathrm{kV}$. Each sample was scanned from $5^{\circ}$ to $50^{\circ}$ at a scan rate of $0.5 \mathrm{~s}$ per step. Phase identification was carried out using the ICDD PDF4 database from the International Center for Diffraction Data and the Jade 7 software, version 5.1.2600, from Materials Data Inc.

Differential thermogravimetry (DTG) and thermogravimetric analysis (TGA) were used to assess the gel structure and mass loss of alkali-activated fly ash-based mortars at elevated temperatures from 23 to $1000^{\circ} \mathrm{C}$. A Precisa PrepASH 129 analyzer was used for executing this test. Powders were placed in alumina crucibles and testing was carried out in an argon atmosphere at a heating rate of $10^{\circ} \mathrm{C} / \mathrm{min}$. Mass loss was recorded by gradually increasing the temperature during the test.

To generate SEM images, small parts of the samples were selected, submerged in acetone (ACS grade) for dehydration, and dried at $(100 \pm 5){ }^{\circ} \mathrm{C}$ for $6 \mathrm{~h}$. A SEM scans the specimen surface using a finely focused beam of electrons and records the signals resulting from the interactions between the electron beam and specimen. In this study, SEM images were produced using a secondary electron detector at an acceleration voltage of $15 \mathrm{kV}$ and a measurement distance of $6-8 \mathrm{~mm}$.

In this study, Atomic force microscopy (AFM) images were taken from the polished samples (1 mm samples were analyzed using a Cypher S AFM microscope). AFM investigates the effects of thermal curing conditions on the surface roughness of geopolymers. The surface topographies of the samples are imaged by AFM using a cantilever to scan the selected regions. The deflections in the cantilever, affected by the lowest and raised regions of the surface, are monitored by a position-sensitive photo diode (PSPD). AFM works by employing a very sharp probe in front of the surface of the sample by maintaining a low level of force between the probe and the surface. 
AFM probes with a primary resonant frequency (f) of $1 / 4300 \mathrm{kHz}$ and a spring constant $(\mathrm{k}$ ) of $1 / 4$ $30 \mathrm{~N} / \mathrm{m}$ and Tap300G were used. Using a typical piezoelectric element with an extremely precise movement, the scanner shifted the probe over the samples. High-resolution images were generated using a combination of the sensitive optical lever moved precisely by the scanner, the sharp tip, and by accurately controlling the probe-sample forces. Before imaging the samples, the system was calibrated using a fused silica reference sample. Wave Metrics Igor Pro v6.34a and Asylum Research AFM Software v14 were used for analyzing the AFM images.

\section{Results and discussion}

\section{Compressive strength}

Fig. 3 shows the compressive strength development in geopolymers under different aging and curing conditions. It could be observed that no significant gel formation occurred in the cured mixtures $\mathrm{M} 1$ (containing the maximum amount of $\mathrm{CaO}$ ), and $\mathrm{M} 3$ and $\mathrm{M} 4$ (containing the maximum amount of $\mathrm{SiO}_{2}$ ) at the ambient temperature. Therefore, the compressive strength of both mixtures was constant when the curing time was increased. The mixtures M3 and M4 contained high amounts of unreacted fly ash particles; therefore, the compressive strength of this composition was the lowest (about 0.5 MPa). Meanwhile, the mixture M1 consisted of unreacted or semireacted particles (about $3 \mathrm{MPa}$ ). At the ambient temperature, the maximum compressive strength was recorded for M2 (almost $10 \mathrm{MPa}$ at 56 days). Unlike other mix compositions, the compressive strength of the mixture M2 increased with an increase in the curing time, which indicates that hydration products are formed during the curing process due to a pozzolanic reaction of lime and ground glass waste together.

Differences among the mixtures are coming from the chemical reactions and dissolution rates of lime with glass powder in fly ash based geopolymers, which depend on various parameters such as aging and curing conditions.

Regardless of the curing age, using thermal curing conditions improved the strength development for the mixture M1 compared to curing at ambient conditions. The strength increase was significant from 7 to 28 days $(\approx 60 \%)$. Later, it will be shown and discussed that thermal curing resulted in occurring a change in the morphology of the matrices and increased the degree of reaction, which made the matrix denser and reduced the cracks caused by shrinkage. However, curing specimens under thermal conditions for more than 28 days had no enhancement on the strength development.

Thermal curing led to accelerate the dissolution rates of different species and improve the matrix compactness in the mixture M2 and subsequently, increased the strength compared to curing at 
the ambient conditions. This strength enhancement is recorded to reach an almost compact matrix and the increasing rate of the strength is reduced by increasing the curing age. Above a certain point, the formation of the chemical reactions introduces additional internal stresses in the compact matrix, which this could damage to the matrix due to lack of space and subsequently, a strength loss may be happened.

The combination of thermal curing and aging had also significant impact on increasing the strengths of the mixtures M3 (almost 23 times increase at 56 days) and M4 (almost 10 times increase at 56 days). Since these mixtures (M3 and M4) contain high amounts of unreacted particles, thermal curing accelerated the dissolution rate and formation of the chemical reactions. These results are confirmed by findings in (Abdollahnejad et al., 2017).

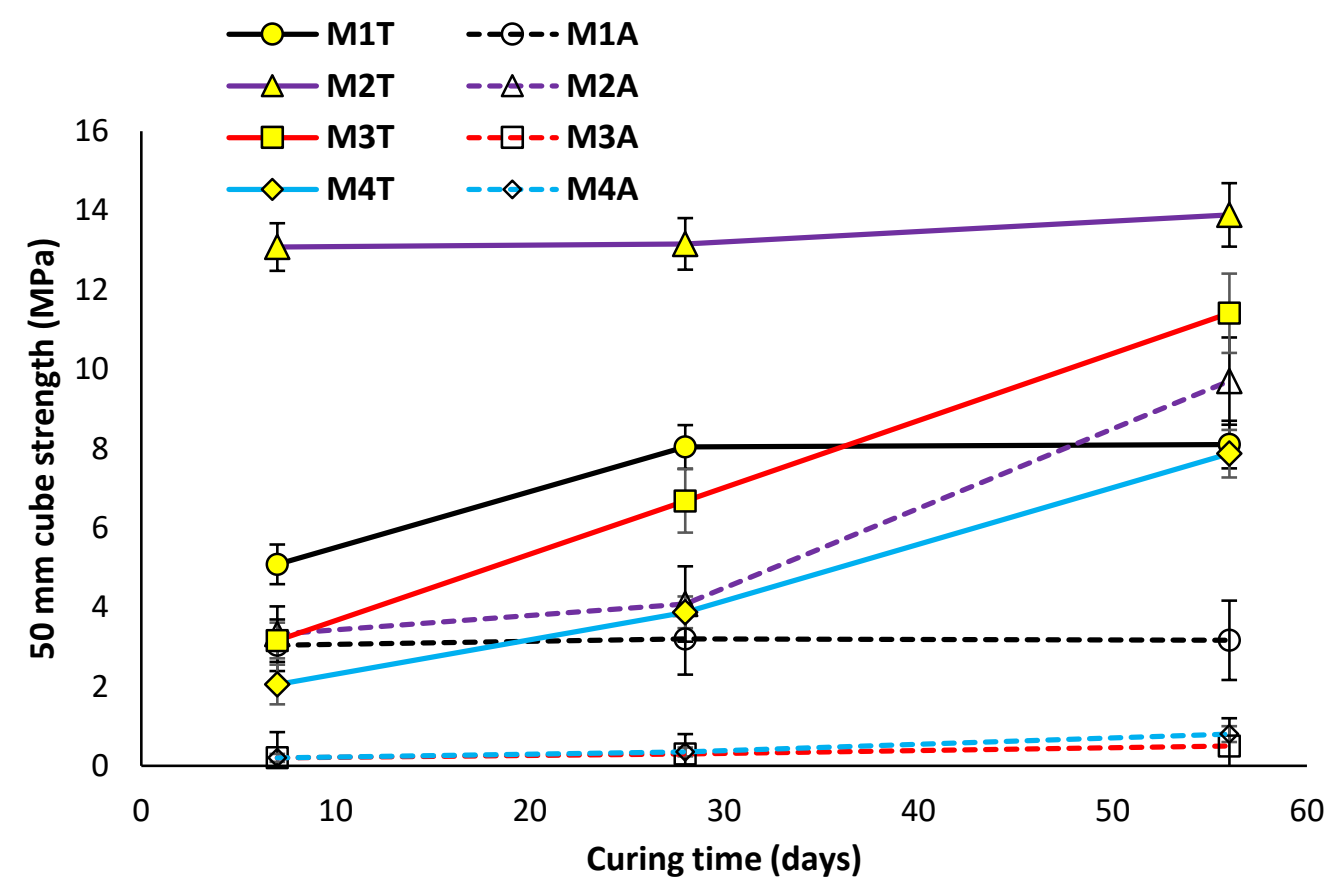

Fig 3. Compressive strength development under different curing conditions

\section{Microstructural analysis}

In the first stage of this study, the influence of the content of waste ground glass and calcium hydroxide on the strength of geopolymers under different curing conditions and periods was studied. Later, on the basis of the compressive strengths developed in different compositions, their morphologies (SEM images), chemical bonds (FTIR analysis), and elemental compositions (EDX analysis) were analyzed under different curing conditions and periods; such 
characterization enables us to understand the effects of waste ground glass and calcium hydroxide on the crystallinity and the effect of crystalline zeolite formation on the strength stability. As the results shown in Fig. 3 indicated that thermal curing exerted a significant effect on the strength development of the mixtures M2 and M3, their mineralogical transitions, gel structure, mass loss, and nano-metric scale properties were studied. The selected mixtures M2 and M3 had minimum and maximum compressive strengths at different curing regimes and periods.

\section{FTIR analysis}

Fig. 4 shows the FTIR spectra of some of the tested specimens. From high to low, the main absorption bands of the mixture M1 are located at around 2360, 1640, 1413, 1080, 972, 879, 783, 690 , and $451 \mathrm{~cm}^{-1}$. The broad bands within the interval of $1648-3466 \mathrm{~cm}^{-1}$ are attributed to the stretching and deformation vibrations of $\mathrm{O}-\mathrm{H}$ and $\mathrm{H}-\mathrm{O}-\mathrm{H}$ bonds in the weakly bound water molecules (Abdollahnejad et al., 2014). The bands at approximately 1413 and $897 \mathrm{~cm}^{-1}$ are ascribed to the presence of calcium carbonate. The band at $1080 \mathrm{~cm}^{-1}$ is attributed to the asymmetric Si-O-T ( $\mathrm{T}=\mathrm{Si}$ or $\mathrm{Al}$ ) bond, which is consistent with the differences in the glass structures. At this wavenumber $\left(1080 \mathrm{~cm}^{-1}\right)$, a sodium aluminosilicate hydrate $(\mathrm{N}-\mathrm{A}-\mathrm{S}-\mathrm{H}) \mathrm{gel}$ is formed as the hydration product (Hajimohammadi et al. 2017). The lower wavenumber of this band is associated with the lower degree of crosslinking of the amorphous phase due to the increased content of calcium in the gel structure. The band at approximately $970 \mathrm{~cm}^{-1}$ is associated with the $\mathrm{T}-\mathrm{O}(\mathrm{T}=\mathrm{Si}$ or $\mathrm{Al})$ bond asymmetric stretching vibrations, which indicates the polymerization of the silicate group and the formation of a calcium silicate hydrate (C-S-H) gel. Owing to thermal curing, higher intensities are observed for the bands in the range of 1080-970 $\mathrm{cm}^{-1}$, which indicates the higher reaction rate of fly ash particles (Ma et al., 2016).

The amorphous gels transform into more ordered structures, which can be tracked by the low wavenumbers. The bands at around $790-776 \mathrm{~cm}^{-1}$ and $690 \mathrm{~cm}^{-1}$ are associated with the O-T-O symmetric stretching vibrations; the bands in the range of $464-443 \mathrm{~cm}^{-1}$ are attributed to the $\mathrm{O}$ T-O bending vibrations and quartz. As depicted in Fig. 4a, the bands at 790-776, 690, and 464$443 \mathrm{~cm}^{-1}$ are particularly evident and relatively sharp for the cured specimen subjected to thermal curing for different periods, suggesting a transition towards more ordered structures. It could be concluded that thermal curing increased the extent of reaction, as compared to curing at the ambient temperature.

Regarding the FTIR results, increasing the curing time under thermal conditions increased the intensities of the bands in the range of $1200-879 \mathrm{~cm}^{-1}$, which indicates that heating affected the amorphous gels and mullite crystals (corresponding to the bands in the range of $1180-1130 \mathrm{~cm}^{-}$ 
${ }^{1}$ ) in the mixture M1. This shows that thermal curing accelerated the transformation of the amorphous gels into more ordered structures.

Fig. 4b illustrates the FTIR spectrum of the mixture M2. Replacing $10 \%$ of calcium hydroxide with $10 \%$ of waste ground glass had no significant effect on the main absorption bands. With respect to the results, it was found that heating affected the intensities and sharpness of the bands after 7 days of curing in the case of mixture M2 due to accelerated activation. Moreover, it was detected that similar amorphous gels were formed in the cured specimens with heating at ages of 28 and 56 days. This means that the transition of amorphous gels into crystalline phases is hindered after 28 days of aging under thermal curing conditions. In general, comparing the FTIR spectra indicated that the intensity of the bands varied owing to the variation in the degree of polymerization of silicates within the remaining gel in the composition as $\mathrm{Si}-\mathrm{O}-\mathrm{Si}$ bonds are formed.

The effects of using $20 \%$ waste ground glass instead of $20 \%$ calcium hydroxide on the bands and intensities of FTIR spectra are shown in Fig. 4c. Thermal curing had a significant effect on the intensity of the reaction bands in the range of $1456-869 \mathrm{~cm}^{-1}$, which affects the formation of amorphous gels and mullite crystals. 


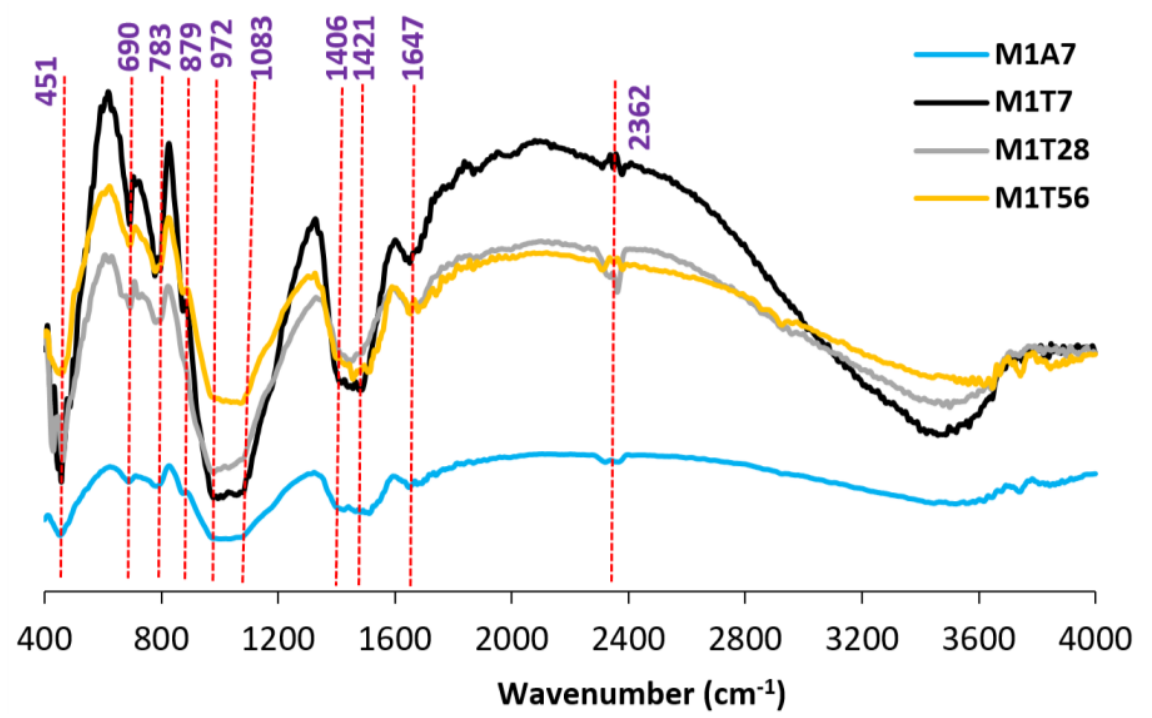

a)

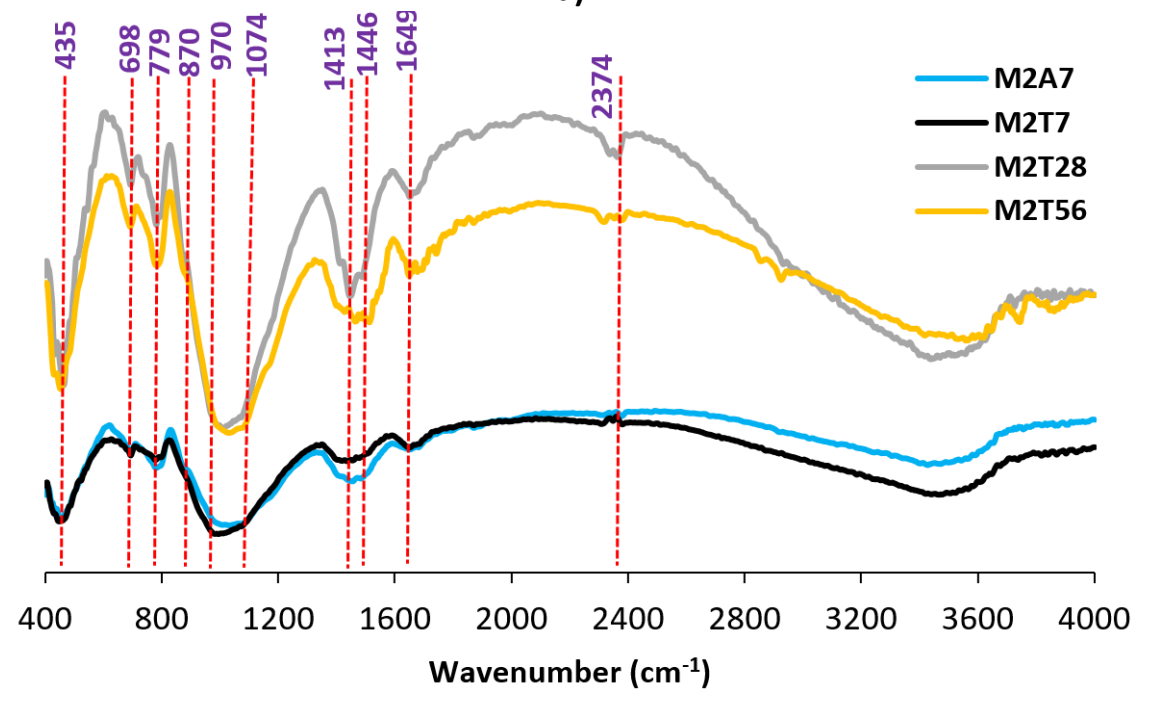

b)

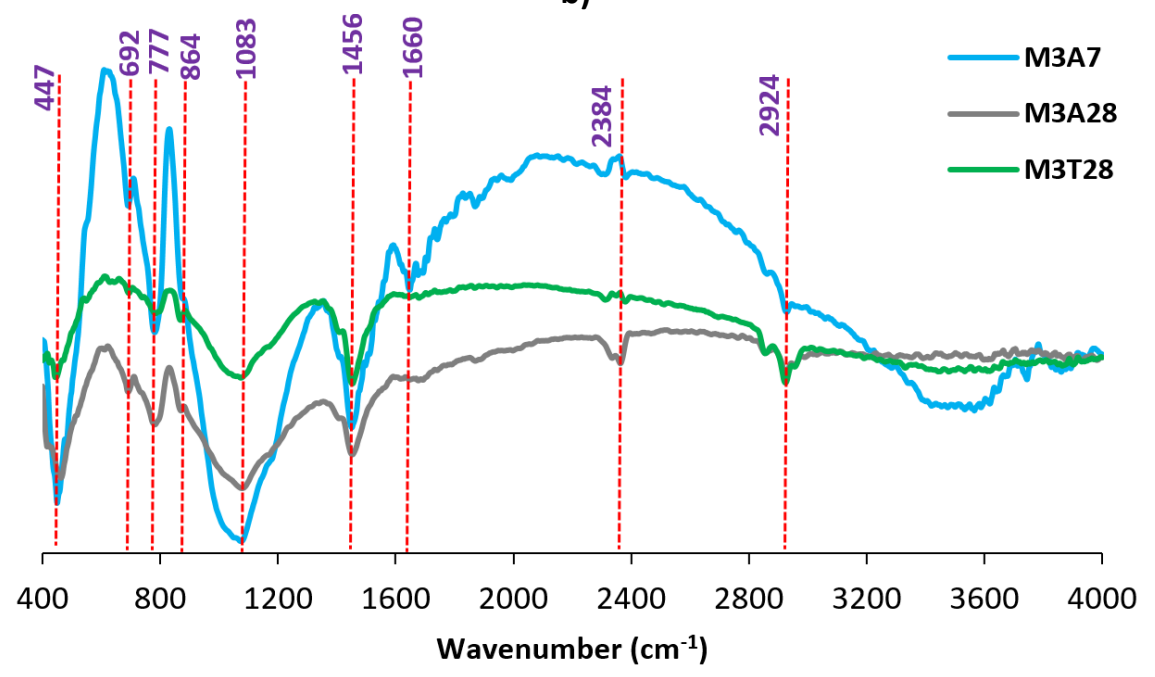

Fig 4. FTIR analysis of the compositions: a) M1, b) M2, and c) M3 


\section{Mineralogical alteration by XRD analysis}

The formation of zeolitic phases, which belong to the analcime $\left(\mathrm{NaAlSi}_{2} \mathrm{O}_{6} \cdot \mathrm{H}_{2} \mathrm{O}\right)$ family, is highly dependent on the chemical composition of the mixture. The mineralogical transitions of different mixtures were investigated by XRD analysis in Fig. 5. Fly ash based geopolymers are commonly synthesized in the temperature range of $20-90{ }^{\circ} \mathrm{C}$ ( Khale and Chaudhary, 2007), where amorphous gels are formed. Thermal curing leads to more crystalline phases or more ordered structures. It could be deduced from its relatively flat diffractogram that the mixture M3A7 exhibited a very limited activation. Increasing the thermal curing time resulted in a higher intensity of characteristic diffraction peaks and reached a certain reaction degree after 56 days of aging under the $80^{\circ} \mathrm{C}$ conditions. This means that a higher degree of crystallization was obtained when compared to the mixture M3 cured at the ambient conditions for 7 days. Moreover, regardless of the curing regime, it was noticed that zeolitic phases are commonly observed in the aged fly ash geopolymers (M3A56 and M3T56).

On the other hand, the potential of transformation of the amorphous gels into more ordered structures, including crystalline zeolites, was slow when the calcium binder content was low (mixture M3); however, thermal curing accelerates this transformation. Using $10 \%$ calcium hydroxide in the mixture M2 made the transition more difficult, as indicated by the XRD results; they were almost similar to the results obtained after 7 days of aging at $80^{\circ} \mathrm{C}$. This result is in agreement with the FTIR result that similar amorphous gels are formed in the cured specimens with heating at ages of 28 and 56 days. Additionally, it could be observed that well-crystallined analcime was detected at 56 days of aging at $80^{\circ} \mathrm{C}$, which indicates a more compact matrix and this affects its mechanical characteristics. The analogue of thermal zeolite synthesis (Murayama et al., 2002; Steenbruggen and Hollman, 2002; Inada et al., 2005; Querol et al., 2002) to geopolymerization is depended to the similarities of the raw materials and activating solutions (Khale and Chaudhary, 2007; Provis et al., 2005b) . The formation of crystalline zeolites changes the local microstructure (stability) and induces inner stresses or even local destruction, which can degrade the mechanical properties (Ma et al., 2016). As indicated in Fig. 3a, crystallization via thermal curing in aged fly ash alkali-activated mortars does not adversely affect the compressive strength and stability. These results are in line with previous studies in which it had been reported that the formation of crystalline zeolites (up to a certain amount) does not have any harmful effect on the strength stability (Ma et al., 2016).

Fig. $5 \mathrm{~b}$ represents the quantitative phase analysis, where the results are normalized to $100 \%$. With respect to the results, the major phases in geopolymer mixtures was characterized quartz. 
Increase of the curing duration led to increase of the analcime crystalline and reducing quartz crystalline in Mixture of M2. After heating for 56 days, the content of mullite crystalline increased from almost $10 \%$ to $35 \%$ in mixture M3. Moreover, the content of the analcime crystalline increased from $3 \%$ to $7 \%$.

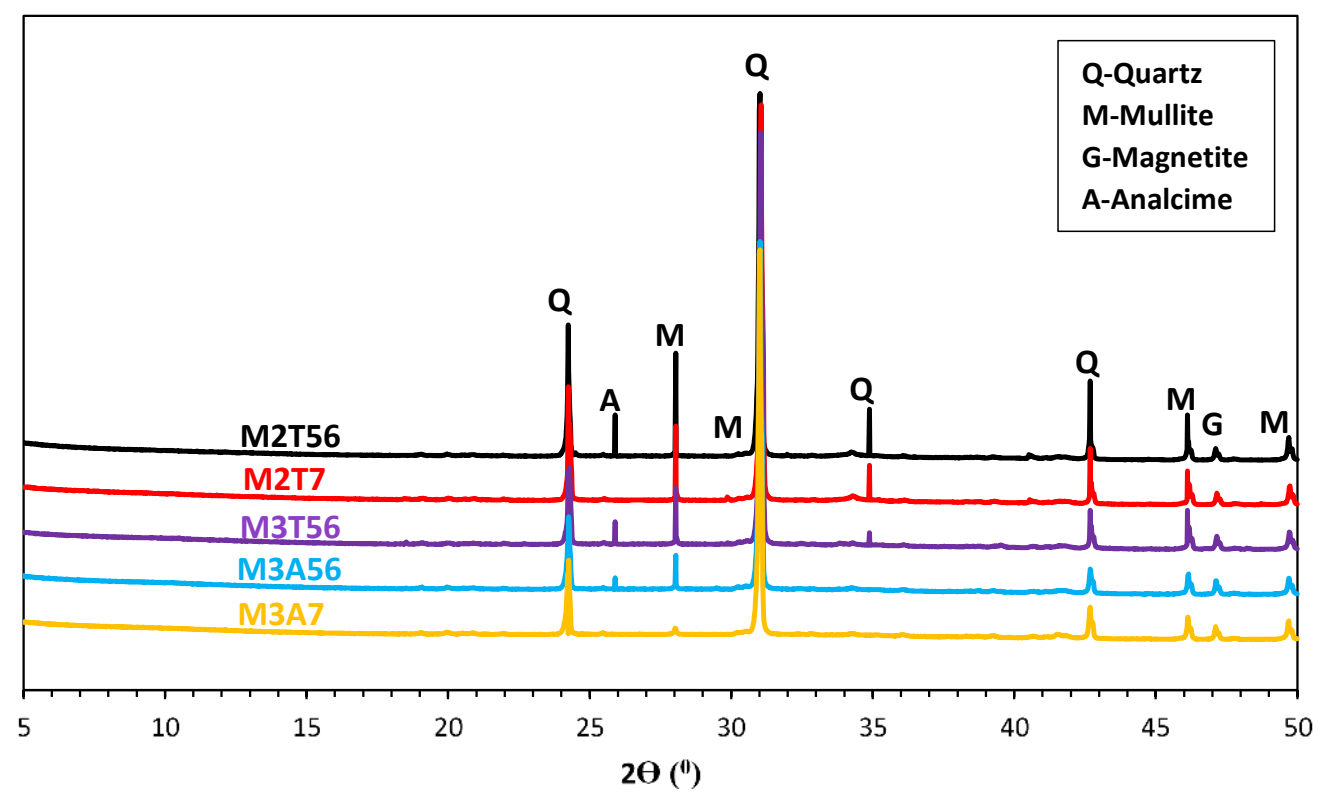

a)

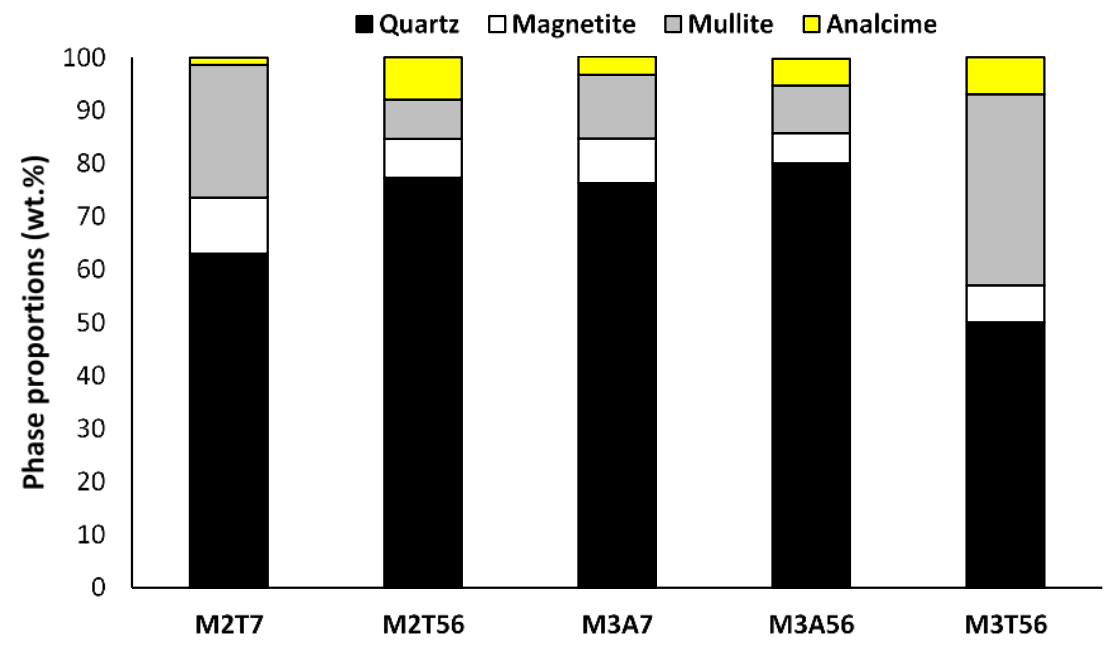

b)

Fig 5. a) XRD analysis of the selected mix compositions; b) Quantitative phase analysis of the compositions by the Rietveld method 


\section{Thermogravimetric analysis (TGA) and differential thermogravimetry (DTG)}

Fig. 6a illustrates the TGA results; it depicts the weight remaining due to heating in different mixtures. Furthermore, the differential thermograms (DTG) of fly ash-based geopolymers are depicted in Fig. 6b, where detectable peaks occurred at various temperatures.

Mass loss in the TGA measurements were recorded over a temperature range of 200 to $800{ }^{\circ} \mathrm{C}$ (Christopher et al., 2016; Nath et al., 2016). Initially, the mixtures contained both free and structural waters. The free water evaporated up to the temperature of $\sim 200^{\circ} \mathrm{C}$. The mass loss in the temperature range of 200 to $800{ }^{\circ} \mathrm{C}$ can be attributed to the loss of structural water. The structural water was bonded the reaction products, namely calcium and/or sodium aluminosilicate hydrate, (N,C)-A-S-H, gel. Thus, losing the structural water gives indirect estimation of the reaction products and structural stability. A greater mass loss implies the formation of a large amount of hydration reaction products and better structural stability. In contrast, less water loss signifies the formation of lesser reaction products and crystallized particles. In section related to the morphology and chemical characterization, it will be discussed that most mixtures in this study belong to the (N,C)-A-S-H gel range and a few mixtures belong to the C-A-S-H gel.

The mixture M2T56 showed the highest mass loss ( 13\%), followed by the mixture M2T7 ( 12\%). Additionally, the lowest mass loss was recorded for the mixture M3A7 ( 11\%). This means that the mixture M2 contained a larger amount of hydration products and exhibited better structural stability when compared to the mixture M3. Regarding the DTA curves, two major endothermic peaks at around $130^{\circ} \mathrm{C}$ and $780{ }^{\circ} \mathrm{C}$ were observed; the large shoulder just below $200{ }^{\circ} \mathrm{C}$ is attributed to the dehydration of the calcium-rich silicate gel [38]. The second destruction phase (at $780{ }^{\circ} \mathrm{C}$ ) could be attributed to the decomposition of calcium carbonate $\left(\mathrm{CaCO}_{3}\right)$ (Shaikh and Supit, 2014) .

The mass loss rate slowed down after $200^{\circ} \mathrm{C}$ owing to the chemically bonded water and $\mathrm{OH}$ groups (Nath et al., 2016). In addition, the DTG curves showed that $\mathrm{Ca}^{2+}$ from calcium hydroxide in the mixture $\mathrm{M} 2$ was responsible for the generation of $\mathrm{CaCO}_{3}$; these results are in good agreement with the reduction of the peak corresponding to the calcium-rich silicate gel.

The mixture M3AT exhibits an endothermic peak at $110^{\circ} \mathrm{C}$, while the mixtures M3A56 and M3T56 exhibited peaks at $130^{\circ} \mathrm{C}$. The different temperatures indicate that there might be some additional gel formation owing to the formation of a more ordered gel structure. Because both the mixtures M2T7 and M2T56 exhibited endothermic peaks at $\sim 132^{\circ} \mathrm{C}$, it can be inferred that thermal curing and increasing curing time had no great effect on the endothermic peaks and formation of additional gels in these mixture. 

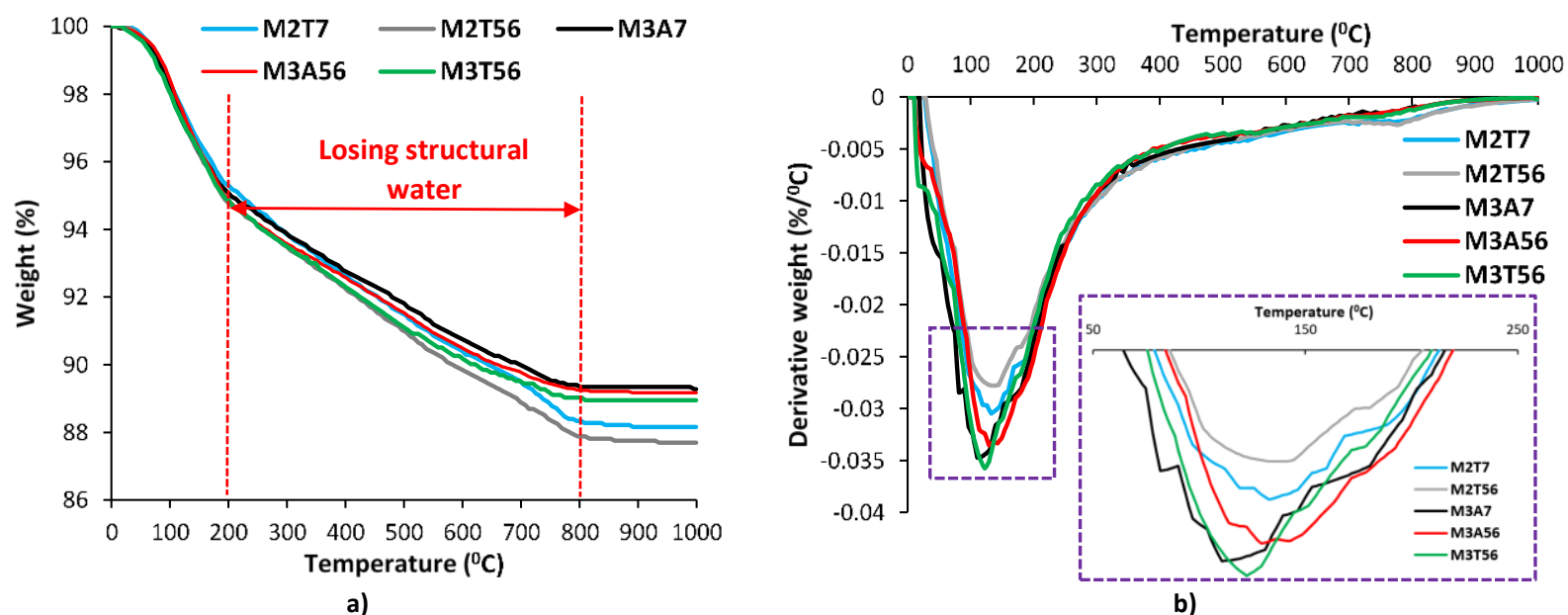

a)

b)

Fig 6. a) TGA and b) DTG results

\section{Morphology and chemical characterization}

Fig. 7 shows the microstructures of different mixtures cured at different ages and conditions. Amorphous sodium aluminosilicate hydrate gels were detected in the M1A7 matrix, which consisted of unreacted or semi-reacted fly ash particles. Moreover, some cracks formed in the matrix of specimen M1A7, which could be due to shrinkage. Comparing the specimens subjected to different aging conditions and curing regimes highlights the differences in their dissolution properties and phase compositions. Thermal curing condition and a higher curing time resulted in a change in the morphology of the matrices and increased the degree of reaction, which made the matrix denser and reduced the cracks caused by shrinkage. The unreacted fly ash particles and the gel were separated by the formation of a crack, indicating a weak adhesion bond between the gel and the particles. It was observed that the amorphous gels transitioned into fused rectangular prisms. These prisms, which are analcime precursors, grew into the pores and yielded denser matrices. The matrix of the high-temperature aged mixture M1 was almost entirely transformed into smaller but interlocked prisms after 28 days, which indicates a rapid and more complete transition in high-temperature aged specimens. Energy-dispersive X-ray spectroscopy (EDX) analysis showed that thermal curing led to an increase in the $\mathrm{Si} / \mathrm{Al}, \mathrm{Ca} / \mathrm{Si}$, and $\mathrm{Na} / \mathrm{Ca}$ contents (see Table 4). However, the highest increase was recorded in the molar ratio of $\mathrm{Na} / \mathrm{Ca}$, which means that some sodium was replaced by $\mathrm{Ca}^{2+}$ in $\mathrm{C}-\mathrm{S}-\mathrm{H}$, and a C,N-A-S-H gel was formed. Replacing calcium by sodium is well-known as a result of ionic exchange mechanisms (GarciaLodeiro et al., 2010; Garcia-Lodeiro et al., 2011). This substitution led to a denser matrix and reduced crack formation; this result is in agreement with FTIR analysis. 
Replacing $10 \% \mathrm{Ca}(\mathrm{OH})_{2}$ by milled waste ground glass significantly reduced crack formation in the matrix compared to the case when $20 \% \mathrm{Ca}(\mathrm{OH})_{2}$ was used to replace fly ash particles. The formed cracks could be caused by alkali-silica reaction (ASA) or alkali-carbonate reaction (ACR) between waste ground glass and other components. The increase of curing time had no great effect on the degree of geopolymerization up to 28 days. On the other hand, it was noticed that the matrix density significantly increased at higher aging times and a very compact matrix formed. The EDX results depict that an increase in the curing time consistently increased the $\mathrm{Ca} / \mathrm{Si}$ ratio; however, no specific increasing or decreasing trend could be observed in other atomic molar ratios.

The morphology of the mixture $\mathrm{M} 2$, which was cured at $80^{\circ} \mathrm{C}$, was not significantly affected by the time of curing. The transition of amorphous gels into fused rectangular prisms was observed (see Fig. 7k). These analcime precursors cannot grow into well-defined single particles due to lack of space. EDX analysis shows that the $\mathrm{Al} / \mathrm{Na}, \mathrm{Ca} / \mathrm{Si}, \mathrm{Si} / \mathrm{Al}$, and $\mathrm{Mg} / \mathrm{Al}$ molar ratios reduced with increasing curing time, while the molar ratio of $\mathrm{Na} / \mathrm{Ca}$ increased. This indicates that a N-A$\mathrm{S}-\mathrm{H}$ gel was formed. Lower $\mathrm{Ca} / \mathrm{Si}$ molar ratios result in the formation of a denser matrix and higher strength stability. A low $\mathrm{Ca} / \mathrm{Si}$ ratio led to a higher degree of polymerization. The formation of the low-calcium semi-crystalline C-S-H gel, which coexists with the geopolymeric gel and the incorporation of $\mathrm{Ca}^{2+}$ into the geopolymeric network as charge balancing action.

With respect to the micrographs in Fig. 71, it was observed that spherical particles of fly ash were polymerized into a bulky mass, but this polymerization was incomplete and a large number of unreacted fly ash particles were visible. By increasing the curing time at the ambient conditions, crystalline zeolites as secondary reaction products were formed. Regarding the XRD and FTIR results, some zeolite particles were observed in the mixtures M3A28 and M3T28. SEM images showed that better crystallized crystals $(\sim 2-5 \mu \mathrm{m}$ size) were formed in the specimens subjected to thermal curing (high temperatures) as compared to the specimens cured at low temperatures ( 1-2 $\mu \mathrm{m}$ size). EDX analysis indicated that thermal curing for 28 days resulted in reducing the molar ratios of $\mathrm{Si} / \mathrm{Al}$ and $\mathrm{Al} / \mathrm{Na}$, while the molar ratio of $\mathrm{Na} / \mathrm{Ca}$ significantly increased. Moreover, it was found that the molar ratio of $\mathrm{Ca} / \mathrm{Si}$ was constant but low. The reduction in the Si/Al ratio led to sialate (Si-O-Al) bonds stronger than siloxane (Si-O-Si) bonds. A large amount of raw materials did not participate in the reaction when the $\mathrm{Si} / \mathrm{Al}$ ratio is high and subsequently the degree of reaction decreased. Thermal curing resulted in a higher dissolution rate of $\mathrm{Si}$ and $\mathrm{Al}$ from precursor particles, which could polymerize into a three-dimensional network structure. 


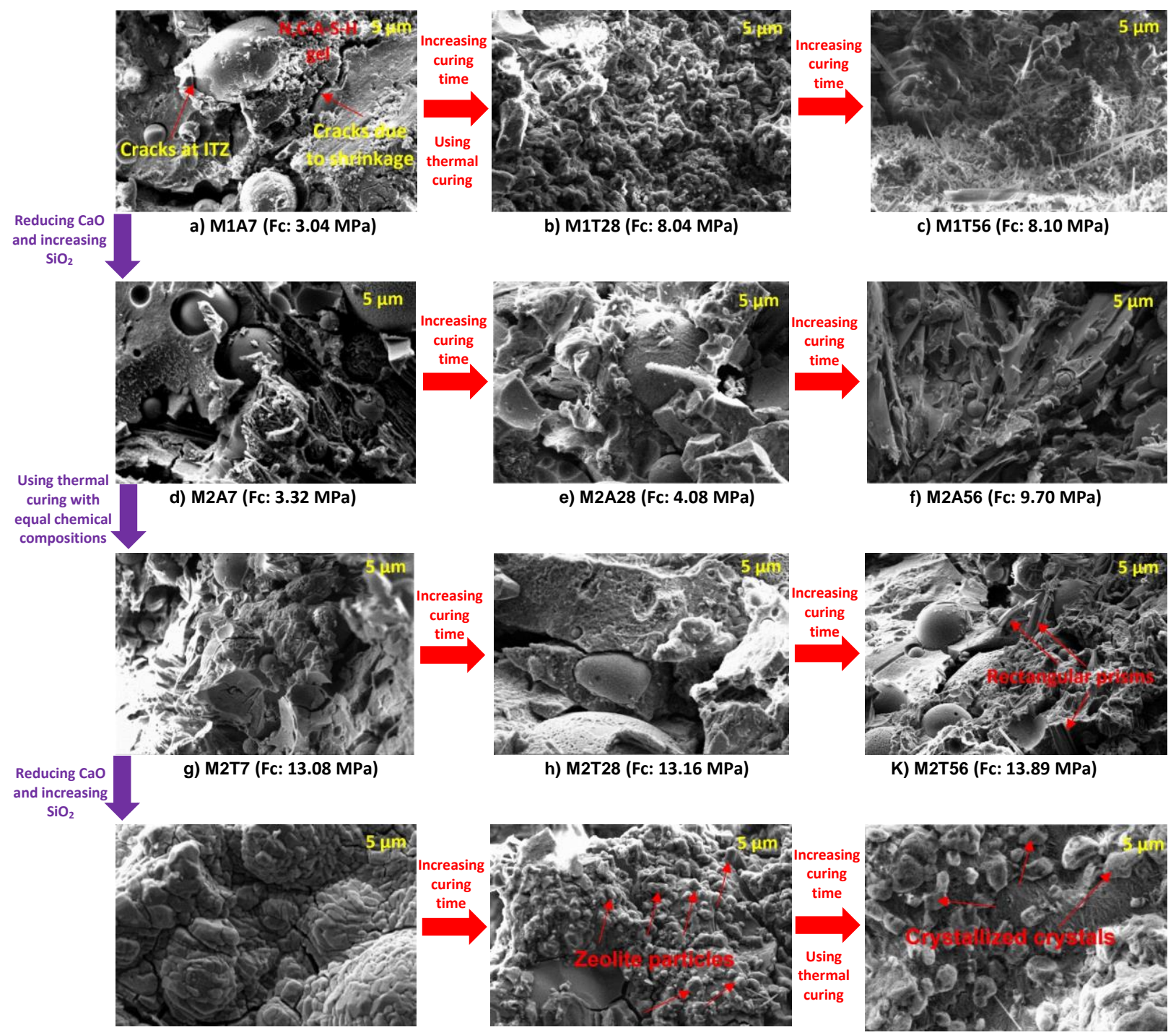

Fig 7. Morphology of the mixtures cured at different conditions and ages

Fig. 8 indicates that the hydrated binders exhibited compositional clusters. The composition ranges which, further to the literature [41-43] characterize the main types of cementitious gels in the binders. A calcium-silicate-hydrate (C-S-H) gel is formed when $\frac{\mathrm{CaO}}{\mathrm{SiO}_{2}} \geq 1$ and $0 \leq \frac{\mathrm{Al}_{2} \mathrm{O}_{3}}{\mathrm{SiO}_{2}} \leq 0.3$ , a calcium aluminum silicate hydrate (C-A-S-H) gel is formed when $0.4 \leq \frac{\mathrm{CaO}}{\mathrm{SiO}_{2}} \leq 1$ and $0.3 \leq \frac{\mathrm{Al}_{2} \mathrm{O}_{3}}{\mathrm{SiO}_{2}} \leq 0.5$, a sodium aluminosilicate hydrate (N-A-S-H) gel is formed when $0 \leq \frac{\mathrm{CaO}}{\mathrm{SiO}_{2}} \leq 0.4$ 
and $\frac{\mathrm{Al}_{2} \mathrm{O}_{3}}{\mathrm{SiO}_{2}} \geq 0.5$, a calcium-(sodium) aluminosilicate hydrate (C-(N)-A-S-H) gel is formed when $0 \leq \frac{\mathrm{CaO}}{\mathrm{SiO}_{2}} \leq 0.4$ and $0.3 \leq \frac{\mathrm{Al}_{2} \mathrm{O}_{3}}{\mathrm{SiO}_{2}} \leq 0.5$, and a calcium silicate hydrate gel containing aluminum (C(A)-S-H) is formed when $\frac{\mathrm{CaO}}{\mathrm{SiO}_{2}} \geq 1$ and $0.3 \leq \frac{\mathrm{Al}_{2} \mathrm{O}_{3}}{\mathrm{SiO}_{2}} \leq 0.5$.

As shown in Fig. 8, most of the points were positions in the N,C-A-S-H gel range and much smaller points were located in the C-A-S-H gel zone; this is a result of the thermal curing conditions. Moreover, the results obviously show that curing time and thermal curing of the mixtures M1 and M3 greatly affected the zeolite precursors, which are easily transformed into crystalline zeolites. Interestingly, it was found that this effect on the mixture M1 (which contains higher content of $\mathrm{CaO}$ ) was on variation of $\mathrm{CaO} / \mathrm{SiO}_{2}$ molar ratio and this effect had a slight effect on increasing $\mathrm{SiO}_{2} / \mathrm{Al}_{2} \mathrm{O}_{3}$. Using thermal curing conditions and increasing cuing time affected greatly on $\mathrm{SiO}_{2} / \mathrm{Al}_{2} \mathrm{O}_{3}$ molar ratio in the mixture $\mathrm{M} 3$ with simultaneously increasing $\mathrm{SiO}_{2}$ and reducing $\mathrm{CaO}$.

Table 4. EDX atomic ratio analysis

\begin{tabular}{|c|c|c|c|c|c|}
\hline Mixture & $\mathrm{SiO}_{2} / \mathbf{A l}_{2} \mathbf{O}_{3}$ & $\mathbf{A l}_{2} \mathbf{O}_{3} / \mathrm{Na}_{2} \mathbf{O}$ & $\mathbf{C a O} / \mathbf{S i O}_{2}$ & $\mathbf{N a}_{2} \mathbf{O} / \mathbf{C a O}$ & $\mathbf{M g O} / \mathbf{A l}_{2} \mathbf{O}_{3}$ \\
\hline M1A7 & 6.54 & 0.59 & 0.36 & 0.70 & 0.18 \\
\hline M1T28 & 6.84 & 0.17 & 0.54 & 1.53 & 0.24 \\
\hline M1T56 & 6.77 & 0.06 & 0.45 & 4.85 & 0.29 \\
\hline M2A7 & 7.83 & 0.51 & 0.15 & 1.61 & 0.20 \\
\hline M2A28 & 6.64 & 0.48 & 0.17 & 1.77 & 0.18 \\
\hline M2A56 & 6.87 & 0.50 & 0.21 & 1.30 & 0.18 \\
\hline M2T7 & 8.96 & 0.72 & 0.19 & 0.79 & 0.24 \\
\hline M2T28 & 6.84 & 0.66 & 0.19 & 1.11 & 0.20 \\
\hline M2T56 & 7.01 & 0.51 & 0.14 & 1.92 & 0.18 \\
\hline M3A7 & 10.32 & 0.08 & 0.02 & 42.47 & 0.29 \\
\hline M3A28 & 13.22 & 0.12 & 0.02 & 23.80 & 0.21 \\
\hline M3T28 & 8.42 & 0.04 & 0.02 & 110.45 & 0.53 \\
\hline
\end{tabular}




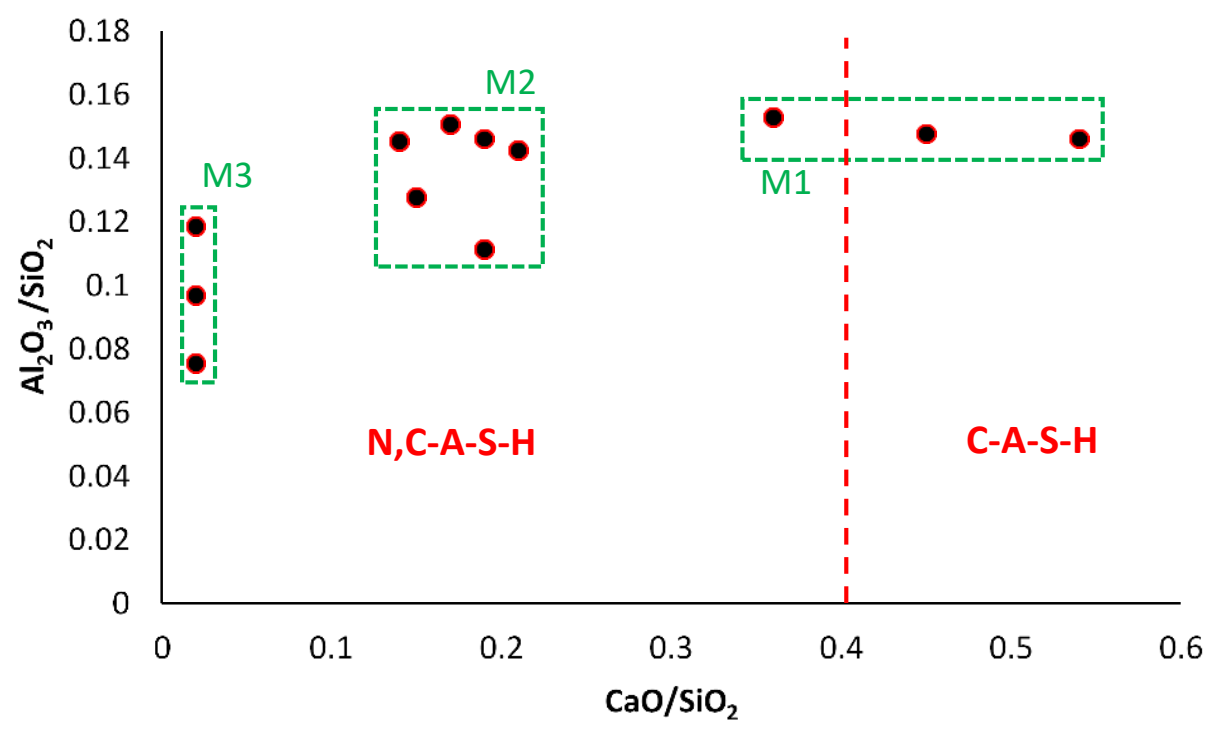

Fig 8. $\mathrm{SiO}_{2} / \mathrm{Al}_{2} \mathrm{O}_{3}$ vs. $\mathrm{CaO} / \mathrm{SiO}_{2}$ ratios for gels participating in the binders (based on EDX findings)

\section{AFM imaging and nano-metric scale properties}

The topography of fly ash-based geopolymers containing waste soda lime silicate glass was characterized by AFM. Fig. 9 presents the three-dimensional surface images of the matrix, where brighter regions are at a higher elevation than darker ones. The images show a greater degree of roughness in the mixture M2T56 compared to others with corrugations of $868 \mathrm{~nm}$. The mixtures containing more un-hydrated particles exhibited more flat surfaces, while particle reaction increased the corrugation height (Mondal et al., 2008). Gel growth via thermal curing at increased curing times increased the degree of roughness due to a greater degree of polymerization and chemical reactions; further, other gel particles might have sufficient energy to migrate to the interface and bond with the existing gel (Davidovits, 2006). With reference to the EDX results, a reduction in the $\mathrm{SiO}_{2} / \mathrm{Al}_{2} \mathrm{O}_{3}$ ratio in mixture $\mathrm{M} 3$ led to the formation of sialate bonds, which is more favored than siloxane bonds due to their lower free energy.

It is worth stating that the authors are aware that more AFM images are needed for concrete results, once the degree of roughness could be different for different zones of a composition. However, the results presented in this study provide a general idea of the degree of roughness of the compositions. 

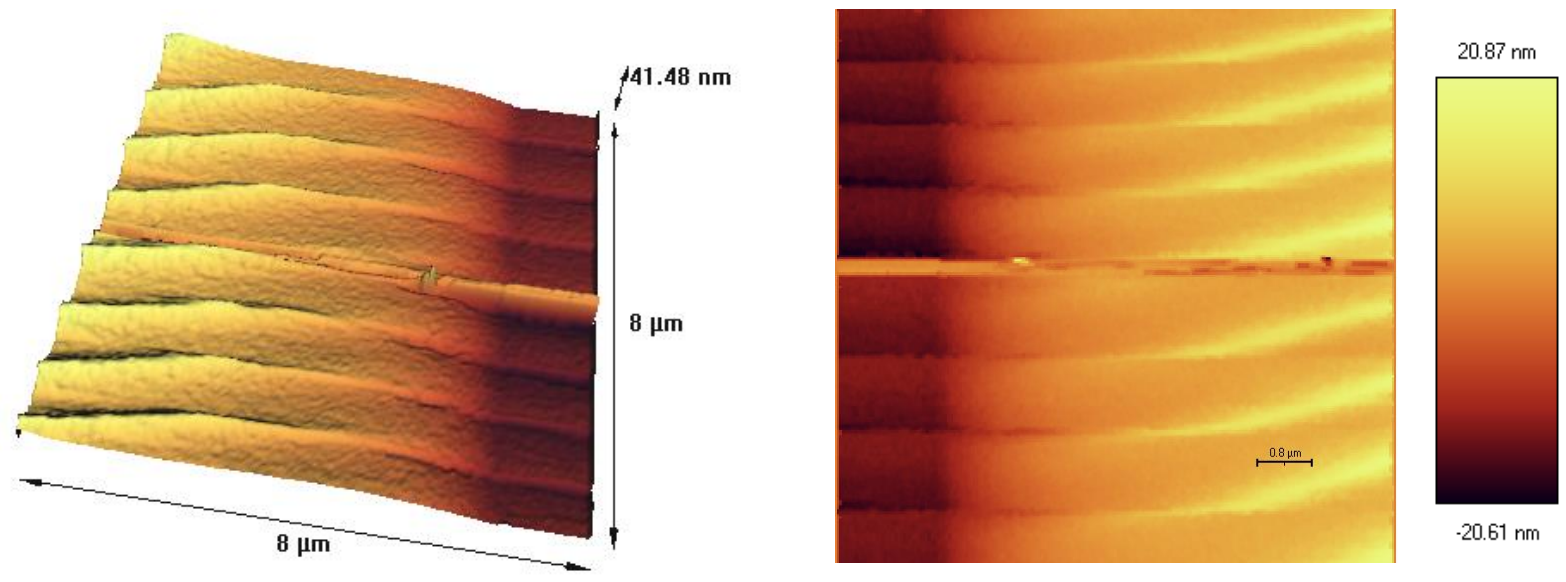

a)
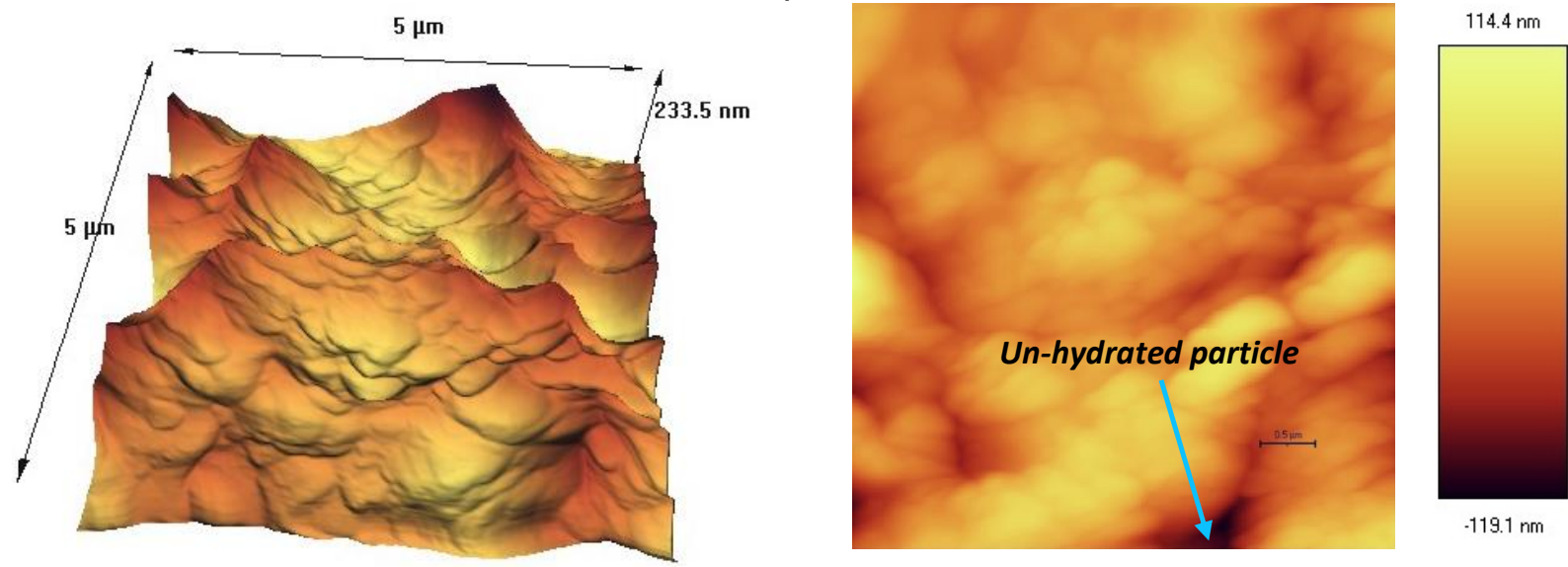

$.119 .1 \mathrm{~nm}$

b)
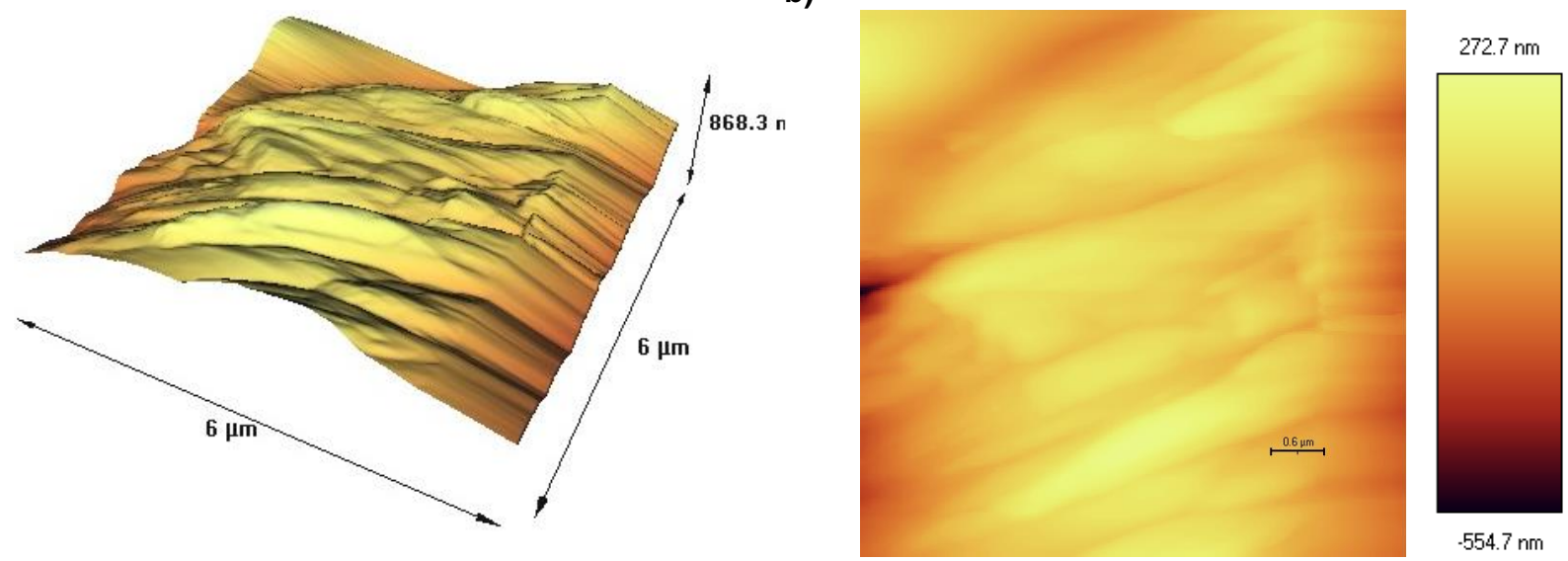

$-554.7 \mathrm{~nm}$

Fig 9. AFM images of the mixtures: a) M3A7, b) M3T28, and c) M2T56

According to the results shown in Fig. 3, in general, the strengths of the samples cured at ambient temperature are lower than those of the samples cured under thermal conditions (Abdollahnejad et al., 2017; Maraghechi et al., 2017). This enhancement is ascribed to the chemical reactions of the compositions. Using EDX analysis, it has been shown that thermal curing decreased the molar 
ratio of $\mathrm{Ca} / \mathrm{Si}$ and increased the molar ratio of $\mathrm{Si} / \mathrm{Al}$ in the samples. These changes in the molar ratios resulted in increasing the compressive strength due to form a denser matrix. The crystallization of fly ash based geopolymers either improves or degrades the mechanical properties. The transition of amorphous gels into more ordered structures causes the local microstructure to change, introducing internal stresses. Regarding the strength development (in Fig. 3), crystallization seems to have no harmful effect on the strength stability of most mixtures. However, negative effects of crystallization are observed in the mixture $\mathrm{M} 1$, when their strengths at 28 days and 56 days are compared. The transition reached to a certain degree and the compressive strength was almost constant from 28 days to 56 days (about $8 \mathrm{MPa}$ ). Therefore, the increase in the compressive strength of $\mathrm{M} 1$ was constant after 28 days of curing, as indicated in Fig. 3.

Moreover, it was noticed that the increase in the compressive strength of the composition M2 reduced gradually with an increase in the curing time (see Fig. 3). The morphology of the compositions indicated a lack of enough space in the matrix, which does not allow growing the precursors into well single particles, owing to which the extent of increase in the compressive strength reduced.

With respect to the results depicted in Fig. 3, the maximum increase in the compressive strength due to the formation of crystalline zeolites was found in the mixture containing the maximum content of waste ground glass (about 23 times for M3T56, as compared to M3A56). In general, it was noticed that the negative impacts of the transition of amorphous gels into crystalline zeolites were minimized by replacing waste ground glass with calcium hydroxide.

It is worth stating that alkali-activated fly ash mortars might have a tendency to form zeolites at ambient conditions over a prolonged period; further investigation is required to prove crystallite formation during long-term curing at the ambient conditions. However, the results of this study imply that such transitions do not have a great effect on the strength.

\section{Relationship between binder transition and the compressive strength}

The general relationship between the molar ratios (based on EDX analysis) and the compressive strength of fly ash alkali-activated mortars was determined using a ternary system. With respect to the results shown in Fig. 10, the maximum compressive strength could be obtained when $0.7 \leq \frac{\mathrm{SiO}_{2}}{\mathrm{Al}_{2} \mathrm{O}_{3}} \leq 0.8,0.02 \leq \frac{\mathrm{CaO}}{\mathrm{SiO}_{2}} \leq 0.05$, and $0.2 \leq \frac{\mathrm{Na}_{2} \mathrm{O}}{\mathrm{CaO}} \leq 0.27$. This means that the molar ratio of $\mathrm{SiO}_{2} / \mathrm{Al}_{2} \mathrm{O}_{3}$ strongly affected the development of the compressive strength; at the same time, the $\mathrm{Na}_{2} \mathrm{O} / \mathrm{CaO}$ molar ratio also exerted a strong effect. On the other hand, the $\mathrm{CaO} / \mathrm{SiO}_{2}$ ratio did 
not exert a strong influence. Because thermal curing strongly affects the dissolution rate of Si and Al from precursor particles, the molar ratio $\mathrm{SiO}_{2} / \mathrm{Al}_{2} \mathrm{O}_{3}$ exerted a very strong influence on the compressive strength. Moreover, replacing calcium with sodium led to a denser matrix and reduced crack formation, which further enhanced the strength.

Fig 10. Ternary diagram for compressive strength analysis

\section{Conclusions}

This study describes that the phase transition behavior of fly ash-based geopolymers is dependent upon a variety of parameters including silica content, calcium content, and aging conditions. The alkali-activated mortars generated from fly ash contain low-calcium materials that are metastable and appropriate for transforming into more ordered structures, including crystalline zeolites. The effect of silica and calcium contents was investigated by replacing fly ash with waste milled glass and calcium hydroxide, respectively. Moreover, different aging conditions were studied under thermal $\left(80^{\circ} \mathrm{C}\right)$ and ambient $\left(25^{\circ} \mathrm{C}\right.$ and $\left.30 \% \mathrm{RH}\right)$ curing conditions for 7 , 28, and 56 days. The following conclusions can be drawn from this study.

Replacing fly ash simultaneously by $10 \%$ waste milled glass and $10 \%$ calcium hydroxide led to the best performance in terms of gel formation at the ambient temperature $\left(25{ }^{\circ} \mathrm{C}\right.$ and $\left.30 \% \mathrm{RH}\right)$, while the transition of gels in the mixtures containing only calcium hydroxide or waste milled glass was very slow at $25^{\circ} \mathrm{C}$. Thermal curing accelerated the transition of amorphous gels to more ordered structures in the alkali-activated mortars containing only calcium hydroxide (20\%) or waste milled glass (20\%).

The level of silica species decreased for the easy transition of amorphous gels into crystallized zeolite of the compositions cured at the thermal curing, while the level of silica species increased for more difficult transition of the amorphous gels to crystallized crystals.

The alkali-activated mortars produced using both $10 \%$ waste milled glass and $10 \%$ calcium hydroxide instead of fly ash (M2) exhibited a more compact microstructure and higher strength compared to others. In addition, microscopic studies illustrated that the resultant gels could be partially transferred into rectangular crystals at 56 days. The transition took place on amorphous gels randomly. Mineralogical and microstructural changes caused by phase transition in this mixture were insignificant, which implies that the stability was significantly increased.

By increasing the waste milled glass content, the negative impact (generating inner stresses or localized damage) of the transition of amorphous gels into crystalline zeolites was minimized. Regardless of the curing conditions, highly crystalline analcime was detected in the alkaliactivated mortars at 28 days aging. 
Regarding the established general relationships detected using a ternary system, the molar ratio of $\mathrm{SiO}_{2} / \mathrm{Al}_{2} \mathrm{O}_{3}$ exerted the greatest impact on the compressive strength development.

\section{Acknowledgements}

The authors sincerely appreciate the collaborative efforts of the Lorestan University (Khoramabad, Iran) and Oulu University (Oulu, Finland) in implementing the study and for their financial support.

\section{References}

Z. Abdollahnejad, P. Hlavacek, S. Miraldo, F. Pacheco-Torgal and J. Barroso (2014) Compressive Strength, Microstructure and Hydration Products of Hybrid Alkaline Cements. Materials Research17, DOI: 10.1590/S1516-14392014005000091.

Z. Abdollahnejad, M. Kheradmand and F. Pacheco-Torgal (2017) Short-term compressive strength of fly ash and waste glass alkali-activated cement based binder (AACB) mortars with two biopolymers. Journal of Materials in Civil Engineering 29, https://doi.org/10.1061/(ASCE)MT.1943-5533.0001920.

L. Alarcon-Ruiz, G. Platret, E. Massieu and A. Ehrlacher (2005) The use of thermal analysis in assessing the effect of temperature on a cement paste. Cement and Concrete Research 35, 609-613.

ASTM C136 / C136M-14, Standard Test Method for Sieve Analysis of Fine and Coarse Aggregates, ASTM International, West Conshohocken, PA, 2014, www.astm.org

ASTM C109 / C109M-16a, Standard Test Method for Compressive Strength of Hydraulic Cement Mortars (Using 2-in. or [50-mm] Cube Specimens), ASTM International, West Conshohocken, PA, 2016, www.astm.org.

ASTM C109 / C109M-16a, Standard Test Method for Compressive Strength of Hydraulic Cement Mortars (Using 2-in. or [50-mm] Cube Specimens), ASTM International, West Conshohocken, PA, 2016, www.astm.org.

R.S. Christopher, J. L. Provis, S. A. Bernal, and K. E. Kurtis (2016) Alkali-activation potential of biomass-coal co-fired fly ash. Cement and Concrete Composites 73, 62-74.

M. Criado, A. Palomo and A. Fernández-Jiménez (2005) Alkali activation of fly ashes. Part 1: effect of curing conditions on the carbonation of the reaction products. Fuel 84, 2048-2054. 
M. Criado, A. Fernández-Jiménez, A.G. de la Torre, M.A.G. Aranda and A. Palomo (2007) An XRD study of the effect of the $\mathrm{SiO}_{2} / \mathrm{Na}_{2} \mathrm{O}$ ratio on the alkali activation of fly ash. Cement and Concrete Research 37, 671-679.

C.S. Cundy and P.A. Cox (2003) The hydrothermal synthesis of zeolites: History and development from the earliest days to the present time. Chemical Reviews 103, 663-701.

J. Davidovits (2006) Geopolymer 2005 Proceedings: Geopolymer, Green Chemistry and Sustainable Development Solutions, 75-78.

A. Fernández-Jiménez, A. Palomo, I. Sobrados and J. Sanz (2006) The role played by the reactive alumina content in the alkaline activation of fly ashes. Microporous Mesoporous Materials 91,111-119.

I. Garcia-Lodeiro, A. Fernández-Jiménez, D.E. Macphee and A. Palomo (2010) Effects of calcium addition on N-A-S-H cementitious gels. Journal of the American Ceramic Society 93, 1934-1940.

I. Garcia-Lodeiro, A. Palomo, A. Fernández-Jiménez and D.E. Macphee (2011) Compatibility studies between N-A-S-H and C-A-S-H gels. Study in the ternary diagram $\mathrm{Na}_{2} \mathrm{O}-$ $\mathrm{CaO}-\mathrm{Al}_{2} \mathrm{O}_{3}-\mathrm{SiO}_{2}-\mathrm{H}_{2} \mathrm{O}$. Cement and Concrete Research 41, 923-931.

I. Garcia-Lodeiro, A. Fernández-Jimenez and A. Palomo (2015) Cements with a low clinker content: versatile use of raw materials. Journal of Sustainable Cement-Based Materials 4 , 140-151.

M. Grutzeck, S. Kwan and M. DiCola (2004) Zeolite formation in alkali-activated cementitious systems. Cement and Concrete Research 34, 949-955.

A. Hajimohammadi, T. Ngo, P. Mendis, A. Kashani and van Deventer J.S.J. (2017) Alkali activated slag foams: The effect of the alkali reaction on foam characteristics. Journal of Cleaner Production 147, 330-339.

D. Hardjito, (2005), Studies of Fly Ash-based Geopolymer Concrete. Curtin University of Technology, Australia.

Y. He, X.M. Cui, X.D. Liu, Y.P. Wang, J. Zhang and K. Liu, (2013) Preparation of selfsupporting NaA zeolite membranes using geopolymers. Journal of Membrane Science 447, 6672.

M. Inada, Y. Eguchi, N. Enomoto and J. Hojo (2005) Synthesis of zeolite from coal fly ashes with different silica-alumina composition. Fuel 84, 299-304.

D. Khale and R. Chaudhary (2007) Mechanism of geopolymerization and factors influencing its development: a review. Journal of Materials Science 42, 729-746. 
R. Lloyd (2009) Accelerated ageing of geopolymers, J.L. Provis, J.S.J. van Deventer (Eds.), Geopolymers: Structure, Processing, Properties and Industrial Applications. Woodhead, Cambridge, UK, 139-166.

X. Ma, Z. Zhang and A. Wang (2016) The transition of fly ash-based geopolymer gels into ordered structures and the effect on the compressive strength. Construction and Building Materials 104, 25-33.

H. Maraghechi, S. Salwocki and F. Rajabipour (2017) Utilisation of alkali activated glass powder in binary mixtures with Portland cement, slag, fly ash and hydrated lime. Materials and Structures 50, https://doi.org/10.1617/s11527-016-0922-5.

M. Mastali, Z. Abdollahnejad and F. Torgal (2018) Performance of waste based alkaline mortars submitted to accelerated carbon dioxide curing. Resources, Conservation and Recycling 129, 12-19.

P. Mondal, S.P. Shah, and L.D. Marks (2008) Use of Atomic Force Microscopy and Nanoindentation for Characterization of Cemetitious Materials at the Nanoscale. American Concrete Institute 254, 41-56.

N. Murayama, H. Yamamoto and J. Shibata (2002), Mechanism of zeolite synthesis from coal fly ash by alkali hydrothermal reaction. International Journal of Mineral Processing 64, 1-17.

S.K. Nath, S. Maitra, S. Mukherjee and S. Kumar (2016) Microstructural and morphological evolution of fly ash based geopolymers. Construction and Building Materials 111, 758-765.

A. Palomo, M. Blanco-Varela, M. Granizo, F. Puertas, T. Vazquez and M. Grutzeck (1999) Chemical stability of cementitious materials based on metakaolin. Cement and Concrete Research 29, 997-1004.

X. Pardal, I. Pochard and A. Nonat (2009) Experimental study of Si-Al substitution in calcium-silicate-hydrate (C-S-H) prepared under equilibrium conditions. Cement and Concrete Research 39, 637-643.

J.L. Provis, G.C. Lukey and J.S.J. van Deventer (2005a) Do geopolymers actually contain nanocrystalline zeolites? a reexamination of existing results. Chemistry of Materials 17, 30753085 .

J.L. Provis and J. Van Deventer (2007) Geopolymerisation kinetics. 2. Reaction kinetic modelling. Chemical Engineering Science 62, 2318-2329.

J.L. Provis, G.C. Lukey, J.S.J., and van Deventer (2005b) Do geopolymers actually contain nanocrystalline zeolites? - A reexamination of existing results. Chemistry of Materials 17, 3075-3085. 
X. Querol, N. Moreno, J.C. Umaa, A. Alastuey, E. Hernández, A. López-Soler and F. Plana (2002) Synthesis of zeolites from coal fly ash: an overview. International Journal of Coal Geology 50, 413-423.

C. Ruiz-Santaquiteria, J. Skibsted, A. Fernández-Jiménez, and A. Palomo (2012) Alkaline solution/binder ratio as a determining factor in the alkaline activation of aluminosilicates. Cement and Concrete Research 42, 1242-1251.

G. Steenbruggen and G.G. Hollman (1998) The synthesis of zeolites from fly ash and the properties of the zeolites products. Journal of Geochemical Exploration 62, 305-309.

F.U.A. Shaikh and S.W.M. Supit (2014) Mechanical and durability properties of high volume fly ash (HVFA) concrete containing calcium carbonate $\left(\mathrm{CaCO}_{3}\right)$ nanoparticles. Construction and Building Materials 70, 309-321.

M. Torres-Carrasco and F. Puertas (2015) Waste glass in the geopolymer preparation. Mechanical and microstructural characterization. Journal of Cleaner Production 90, 397-408.

J. Van Jaarsveld, J. Van Deventer and G. Lukey (2002) The effect of composition and temperature on the properties of fly ash-and kaolinite-based geopolymers. Chemical Engineering Journal 89, 63-73.

J.G.S. Van Jaarsveld, J.S.J. Van Deventer and L. Lorenzen (1998) Factors affecting the immobilization of metals in geopolymerized flyash, Metallurgical and Materials Transactions B 29, 283-291.

F. Winnefeld, A. Leemann, M. Lucuk, P. Svoboda and M. Neuroth (2010) Assessment of phase formation in alkali activated low and high calcium fly ashes in building materials. Construction and Building Materials 24, 1086-1093.

R. Xu, W. Pang, J. Yu, Q. Huo and J. Chen (2007) Chemistry of Zeolites and Related Porous Materials: Synthesis and Structure. John Wiley \& Sons, Singapore, 287-289.

C. Xuemin, H. Yan, L. Leping and C. Jinyu (2011) NaA zeolite synthesis from geopolymer precursor. MRS Communications 1, 49-51.

H. Yan, C. Xue-Min, M. Jin, L. Liu, X.-. Liu, and J.-. Chen (2012) The hydrothermal transformation of solid geopolymers into zeolites. Microporous Mesoporous Materials 161, 187192.

J. Zhang, Y. He, Y. Wang, J. Mao and X. Cui (2014) Synthesis of a self-supporting faujasite zeolite membrane using geopolymer gel for separation of alcohol/water mixture. Materials letter 116, 167-170.

Z. Zhang, L. Li, D. He, X. Ma, C. Yan and H. Wang (2016) Novel self-supporting zeolitic block with tunable porosity and crystallinity for water treatment. Materials Letter 178, 151-154. 